\title{
Reduced pim-1 expression increases chemotherapeutic drug sensitivity in human androgen-independent prostate cancer cells by inducing apoptosis
}

\author{
XING ZHANG $^{1}$, YUYAN SUN ${ }^{1}$, PENG WANG ${ }^{1}$, CHANGFU YANG ${ }^{1}$ and SHENGWEI LI $^{2}$ \\ Departments of ${ }^{1}$ Urology and ${ }^{2}$ Surgery of Chinese Medicine, \\ Yangzhou Traditional Chinese Medicine Hospital Affiliated to Nanjing University of Chinese Medicine, \\ Yangzhou, Jiangsu 225002, P.R. China
}

Received September 30, 2018; Accepted May 16, 2019

DOI: $10.3892 /$ etm.2019.7862

\begin{abstract}
Chemotherapeutic drug resistance is an obstacle for the successful therapy of prostate cancer. The aim of the present study was to identify the effects of proto-oncogene serine/threonine-protein kinase pim-1 (pim-1) in the proliferation of chemotherapeutic drug-resistant prostate cancer cells. Androgen-independent human prostate cancer cell lines PC3 and DU145 were used in the current study. Cisplatin-sensitive PC 3 cells and cisplatin-resistant PC3/DDP cells were used in drug-resistance assays. The expression levels of pim-1, permeability glycoprotein (p-gp), caspase- 3 and cleaved caspase-3 were determined using western blotting analysis; pim-1 was knocked down using pim-1-specific short hairpin RNA (shRNA); cell viability was determined using MTT assay and $\mathrm{IC}_{50}$ values of the chemotherapeutic drugs in human prostate cancer cells tested were calculated using GraphPad 5 software. Androgen-independent human prostate cancer cell lines PC3 and DU145 were transfected with pim-1-targeted or control shRNA, and MTT results revealed that pim-1 knockdown significantly inhibited PC3 and DU145 cell viability in a time-dependent manner $(\mathrm{P}<0.01)$. Cisplatin-resistant cells PC3/DDP exhibited higher levels of pim-1 and p-gp expression compared with cisplatin-sensitive PC3 cells; and pim-1 knockdown markedly increased chemotherapeutic drug sensitivity in PC3/DDP cells. In addition, pim-1 knockdown increased chemotherapeutic drug sensitivity in PC3/DDP cells. The molecular mechanism of drug sensitivity was discovered to be partly due to pim-1 knockdown, as it significantly increased apoptosis in cisplatin-resistant PC3/DDP cells. The present
\end{abstract}

Correspondence to: Dr Shengwei Li, Department of Surgery of Chinese Medicine, Yangzhou Traditional Chinese Medicine Hospital Affiliated to Nanjing University of Chinese Medicine, 577 Middle Road, Wenchang, Yangzhou, Jiangsu 225002, P.R. China

E-mail: lishengwei8688@163.com

Key words: pim-1, interference, prostate cancer, chemotherapeutic drug resistance study may provide a new strategy for the therapy of prostate cancer.

\section{Introduction}

Prostate cancer is one of the most common tumors observed in male genitourinary system, and is the second leading cause of cancer-associated mortality in men with the highest prevalence in older men $(1,2)$. Chemotherapy is a commonly applied method for cancer treatment. At present, a large number of drugs, including abiraterone acetate, bicalutamide and cabazitaxel have been approved by the U.S. Food and Drug Administration for the treatment of human prostate cancer $(3,4)$. Androgen deprivation therapy has demonstrated a degree of effectiveness against androgen-dependent prostate malignancies $(5,6)$. However, as prostate cancer advances it frequently transforms into androgen-independent prostate cancer (AIPC), reducing the efficacy of androgen deprivation therapy (7). In addition, drug resistance remains an obstacle to successful therapy, as it may lead to an aggressive and lethal form of prostate cancer, for which there is a lack of effective treatment.

Proto-oncogene serine/threonine-protein kinase pim-1 (pim-1) is a proto-oncogene encoded by the pim-1 gene (8). It has been reported that pim-1 serves important roles in apoptosis, proliferation and differentiation of cancer cells and the progression of cancer (9). In particular, pim-1 serves an important role in the induction or suppression of cell cycle progression and apoptosis. In a previous study, immunohistochemical analysis was used to characterize the expression patterns of pim-1 in high grade prostatic cancer tissues and normal tissues (10). The expression of pim-1 in prostate cancer tissues was demonstrated to be significantly higher compared with that in normal prostate tissues and benign prostatic hyperplasia (9). In addition, pim-1 expression has been demonstrated to negatively correlate with clinical outcome after therapy.

Gene therapy has brought about a breakthrough for the treatment of prostate cancer, and a number of studies have identified a substantial number of genes that may be potential targets for the treatment of this malignancy $(11,12)$. In the present study, AIPC cell lines PC3 and DU145, which do not respond to androgens, glucocorticoids or epidermal/fibroblast 
growth factors, were selected as models $(13,14)$. In addition, the cisplatin-resistant subline of PC3, PC3/DDP, was used. In the present study, an RNA-interference approach was utilized to investigate the effects of pim-1 knockdown on PC3 and DU145 cell proliferation. In addition, the effects of pim-1 on PC3/DDP cell sensitivity to chemotherapeutic drugs were investigated. The results of the present study may provide new ideas for the therapy of AIPC.

\section{Materials and methods}

Cell lines, reagents and antibodies. Human prostate cancer cell lines PC3 and DU145 were purchased from American Type Culture Collection and cultured in DMEM (HyClone; GE Healthcare Life Sciences) supplemented with $10 \%$ fetal calf serum (cat. no. SH30071.03; HyClone; GE Healthcare Life Sciences), $100 \mathrm{U} / \mathrm{ml}$ penicillin and $100 \mu \mathrm{g} / \mathrm{ml}$ streptomycin (cat. no. 15140122, Gibco ThermoFisher Scientific, Inc.) at $37^{\circ} \mathrm{C}$ and the concentration of $\mathrm{CO}_{2}$ was $5 \%$. MTT was obtained from Sigma-Aldrich (Merck KGaA). Pim-1 short hairpin RNA (shRNA) plasmid (human; cat. no. sc-36225-SH) and control shRNA plasmid-A (cat. no. sc-108060) were purchased from Santa Cruz Biotechnology Inc. The Lipofectamine ${ }^{\circledR} 3000$ transfection reagent was obtained from Invitrogen (Thermo Fisher Scientific, Inc.).

Cell transfection. PC3 or DU145 cells were seeded into 24-well plates at a density of $1 \times 10^{5}$ cells/well. After $8 \mathrm{~h}$ of culture, the cells were transfected with pim-1-specific or control shRNA for $6 \mathrm{~h}$ using Lipofectamine 3000 according to manufacturer's protocols. Briefly, $1 \mu \mathrm{g}$ of pim-1 or control shRNA plasmid and $2 \mu \mathrm{l}$ of Lipofectamine 3000 were diluted in $100 \mu 1$ Opti-MEM (Gibco; ThermoFisher Scientific, Inc.) each and incubated at room temperature for $5 \mathrm{~min}$. The two solutions were mixed gently at room temperature to a total volume of $200 \mu \mathrm{l}$ and incubated for a further $15 \mathrm{~min}$. This transfection mixture was then gently added into each well. Media containing the transfection mixture was subsequently replaced with fresh medium supplemented with 10\% FBS in each well $6 \mathrm{~h}$ after transfection. The cells were then cultured for 24, 48, 72 and $96 \mathrm{~h}$ before detection.

Reverse transcription-quantitative PCR (RT-qPCR). Total RNA was extracted from pim-1 shRNA and control shRNA-transfected cells $\left(1 \times 10^{6}\right.$ cells $)$ using RNApure kit (BioTeke Corporation) and reverse transcribed using RevertAid RT Reverse Transcription kit (Invitrogen; Thermo Fisher Scientific, Inc.) for $5 \mathrm{~min}$ at $25^{\circ} \mathrm{C}, 60 \mathrm{~min}$ at $42^{\circ} \mathrm{C}$ and $5 \mathrm{~min}$ at $70^{\circ} \mathrm{C}$. Pim-1 mRNA levels were detected by qPCR amplification using SYBR green (cat. no. 4385610; Thermo Fisher Scientific, Inc.) and an Applied Biosystems 7500 Real-Time PCR System (Applied Biosystems; Thermo Fisher Scientific, Inc.). Human pim-1 primer pair (cat. no. OOCA01281) was purchased from BioPike, LLC. $\beta$-actin was used as the internal reference gene. The primers for $\beta$-actin were: Forward, 5'-AGAGGGAAATCG TGCGTGAC-3' and reverse, 5'-CAATAGTGATGACCTGGC CGT-3'. The thermocycling conditions were: $94^{\circ} \mathrm{C}$ for $2 \mathrm{~min}$, followed by 30 cycles of $95^{\circ} \mathrm{C}$ for $10 \mathrm{sec}$ and $57^{\circ} \mathrm{C}$ for $30 \mathrm{sec}$. Each sample was run in triplicate. Relative expression levels were determined using the $2^{-\Delta \Delta \mathrm{Cq}}$ method (15).
MTT viability assay. MTT assay was performed as previously described $(16,17)$. Briefly, PC3 and DU145 cells $\left(1 \times 10^{5}\right.$ cells/well) were seeded into 48 -well plates. After $8 \mathrm{~h}$ incubation, cells were transfected with pim-1 or control shRNA for $6 \mathrm{~h}$, before being subsequently cultured for 48 , 72 and $96 \mathrm{~h}$. Next, $20 \mu \mathrm{l}$ MTT agent (stock concentration $5 \mathrm{mg} / \mathrm{ml}$ ) was added into each well followed by a further $4 \mathrm{~h}$ of incubation. Finally, $200 \mu \mathrm{l}$ DMSO was added into the medium to dissolve the formazan crystals and incubated for $15 \mathrm{~min}$ at $37^{\circ} \mathrm{C}$, and formazan was measured at a wavelength of OD490. The plates were read on a microplate reader (iMark ${ }^{\mathrm{TM}}$; Bio-Rad Laboratories, Inc.) before the data were analyzed. Survival rate $(\%)=100 \times(O D 490$ value of tested sample/OD 490 value of untreated cells).

$I C_{50}$ determination. PC3 and their drug resistant counterpart PC3/DDP cells (Shanghai Aulu Biological Technology, Co., Ltd.) were first seeded into 96 -well plates $\left(3 \times 10^{4}\right.$ cells/well). Following 8-h culture at $37^{\circ} \mathrm{C}, \mathrm{PC} 3$ and PC3/DDP cells were treated with drugs used for chemotherapy, including cisplatin, 5-fluorouracil and doxorubicin at $37^{\circ} \mathrm{C}$ for $48 \mathrm{~h}$. The drug concentrations of each drug applied were as follows: 1000, $500,250,125,62.5,31.25,15.62,7.81,3.90$ and $1.95 \mu \mathrm{g} / \mathrm{ml}$, as previously described $(18,19)$. Cells treated with $0.1 \%$ DMSO were used as the negative controls. Cell viability was determined using MTT assay and the $\mathrm{IC}_{50}$ values were calculated using GraphPad Prism 5 software (GraphPad Software, Inc.).

Western blotting. Cells $\left(1 \times 10^{6}\right.$ cells/well) were collected and lysed using RIPA buffer (Beyotime Institute of Biotechnology), and the concentration of total proteins were determined using bicinchoninic acid assay. The proteins (25 $\mu \mathrm{g} / \mathrm{lane})$ were separated by $10 \%$ SDS-PAGE as previously described $(20,21)$, and transferred to PVDF membranes at a constant current of $300 \mathrm{~mA}$ for $1 \mathrm{~h}$. The PVDF membranes were blocked using 5\% non-fat milk diluted in TBS supplemented with $0.1 \%$ Tween-20 (TBST) for $1 \mathrm{~h}$ at room temperature. The membranes were subsequently incubated overnight at $4^{\circ} \mathrm{C}$ with primary antibodies against pim-1 (cat. no. ab94603; 1:10,000; Abcam), anti- $\beta$-actin (mouse monoclonal; cat. no. sc-47778; 1:10,000; Santa Cruz Biotechnology, Inc.) and anti-p-gp (cat. no. ab242104; 1:500; Abcam). The membranes were washed three times using TBST before they were incubated with horseradish peroxidase-conjugated goat anti-mouse (cat. no. sc-2031) or goat anti-rabbit secondary antibodies(cat. no. sc-2004) (1:10,000; Santa Cruz Biotechnology, Inc.) for $1 \mathrm{~h}$ at room temperature. The membrane was washed a further three times with TBST buffer and were subsequently visualized using chemiluminescent ECL reagent kit (cat. no. WBKLS0500; EMD Millipore; Merck KGaA). $\beta$-actin used as the loading control and for normalization. ImageJ software (version 1.8.0; National Institutes of Health) was used for densitometry.

Annexin V-FITC/propidium iodide (PI) staining analysis. PC3 and PC3/DDP cells $\left(5 \times 10^{5}\right.$ cells/per well) were first seeded into 6-well plates. Following $8 \mathrm{~h}$ incubation, the cells were transfected for $6 \mathrm{~h}$ with pim-1 or control shRNA and cultured for $24 \mathrm{~h}$ and treated with $0.1 \mathrm{mg} / \mathrm{ml}$ of cisplatin for $48 \mathrm{~h}$. Cell apoptosis was assessed using annexin V-FITC/PI staining according to manufacturer's protocol (Annexin V kit; sc-4252 
A PC3 cells Du145 cells

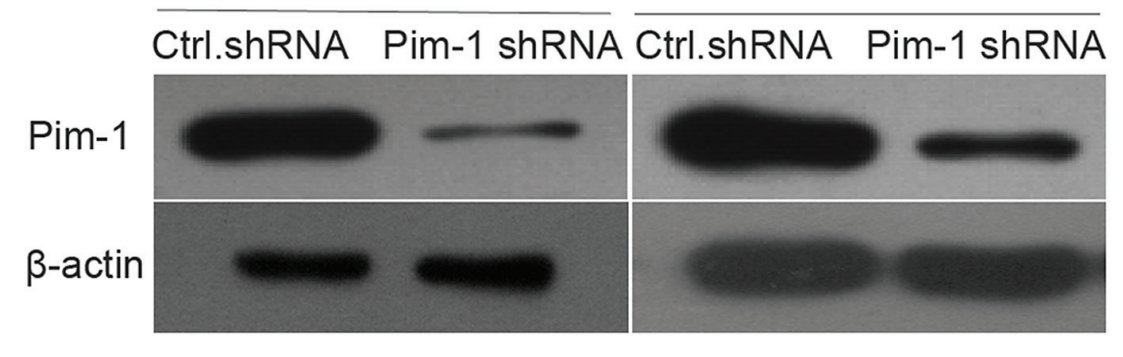

B

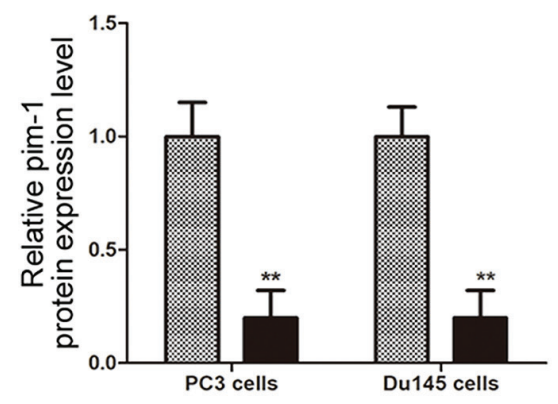

Figure 1. Pim-1 expression is knocked down by pim-1 shRNA in prostate cancer cell lines. (A) The prostate cancer cell lines PC3 and DU145 were transfected with pim-1 or control shRNA, and Pim-1 protein expression levels were determined using western blotting at $48 \mathrm{~h}$ post-transfection. (B) Densitometric analysis of protein expression were semi-quantified by densitometry. PC-3 or DU145 cells transfected with control shRNA were used as negative controls. ${ }^{* *} \mathrm{P}<0.01$ vs. Ctrl. shRNA. Ctrl, control; Pim-1, proto-oncogene serine/threonine-protein kinase pim-1; shRNA, short hairpin RNA.

AK; Santa Cruz Biotechnology, Inc.). Briefly, the cells were digested using $0.25 \%$ trypsin for 1-2 min before being washed twice with ice-cold PBS. The cells were then collected by centrifugation at $800 \mathrm{x}$ g for $5 \mathrm{~min}$ at $4^{\circ} \mathrm{C}$ and subsequently resuspended in binding buffer (10 mM HEPES-NaOH; $25 \mathrm{mM} \mathrm{CaCl}_{2} ; 144 \mathrm{mM} \mathrm{NaCl} ; \mathrm{pH}$ 7.4). Annexin V-FITC $(0.1 \mu \mathrm{g} / \mu \mathrm{l})$ and PI $(0.05 \mu \mathrm{g} / \mu \mathrm{l})$ were subsequently added to the cells, followed by incubation in the dark for $15 \mathrm{~min}$ at room temperature. Fluorescence-activated cell sorting (FACS) analysis was performed by collecting 10,000 cells for each sample using BD LSRFortessa X-20 flow cytometer and BD FACSDiva $^{\mathrm{TM}}$ software version 6.0 (BD Biosciences).

Statistical analysis. Data were analyzed using SPSS statistical package (version 13; SPSS, Inc.). Two sets of independent samples were analyzed using Student's t-test. Comparisons between multiple groups were analyzed using ANOVA followed by Tukey test. The experiments were repeated three times, and the results were expressed as the mean \pm standard error of the mean. $\mathrm{P}<0.05$ was considered to indicate a statistically significant difference.

\section{Results}

Pim-1 knockdown by shRNA inhibits proliferation of prostate cancer cell lines PC3 and DU145. The role of pim-1 in prostate cancer cell viability was examined. PC3 and DU145 cells were transfected with pim-1-specific shRNA or control shRNA. Pim-1 protein expression was successfully knocked down by pim-1 shRNA in PC3 and Du145 cells $48 \mathrm{~h}$ following transfection (Fig. 1). The pim-1 shRNA-transfected PC3 and DU145 cells were subsequently cultured for 48, 72 and $96 \mathrm{~h}$ after transfection. Pim-1 mRNA and protein expression were significantly reduced by pim-1 shRNA transfection in PC3 and DU145 cells at each timepoint; compared with cells transfected with control shRNA (Fig. 2A-D). In addition, cell viability was significantly reduced in PC3 and DU145 cells transfected with pim-1 shRNA compared with cells transfected with control shRNA after 48, 72 and $96 \mathrm{~h}(\mathrm{P}<0.05$; Fig. 2E). No statistically significant differences were observed between untreated cells and those transfected with control shRNA in terms of cell viability $(\mathrm{P}>0.05)$.

Expression of pim-1 and permeability glycoprotein ( $p$-gp) is markedly higher in PC3/DDP cells than that in PC3 cells. Drug resistance is an obstacle to successful therapy in a number of human malignancies. In the present study, the PC3 cell line and its cisplatin-resistant subline PC3/DDP were used as models to investigate the role of pim-1 in prostate cancer drug resistance. Pim-1 and p-gp protein levels were determined using western blotting in cisplatin-sensitive PC3 and resistant PC3/DDP cells. The expression of $\mathrm{p}$-gp was significantly increased in PC3/DDP cells compared with the PC3 cells ( $\mathrm{P}<0.01$; Fig. 3A). Importantly, pim-1 expression was also demonstrated to be significantly higher in PC3/DDP cells compared with that in PC3 cells $(\mathrm{P}<0.01)$.

Determination of IC50 values to cisplatin, 5-flurouracil and doxorubicin in PC3 and PC3/DDP cells. The half maximal inhibitory concentration $\left(\mathrm{IC}_{50}\right)$ was subsequently determined for cisplatin, 5-fluorouracil and doxorubicin in inhibiting prostate cancer cell viability using MTT assay. The $\mathrm{IC}_{50}$ values for cisplatin in PC3 cells and PC3/DDP cells were 98.21 and $625.50 \mu \mathrm{g} / \mathrm{ml}$, respectively (Fig. 3B); whereas the $\mathrm{IC}_{50}$ values for 5-fluorouracil in PC3 cells and PC3/DDP cells were 146.1 and $1473.0 \mu \mathrm{g} / \mathrm{ml}$, respectively (Fig. 3C). The $\mathrm{IC}_{50}$ values 
A

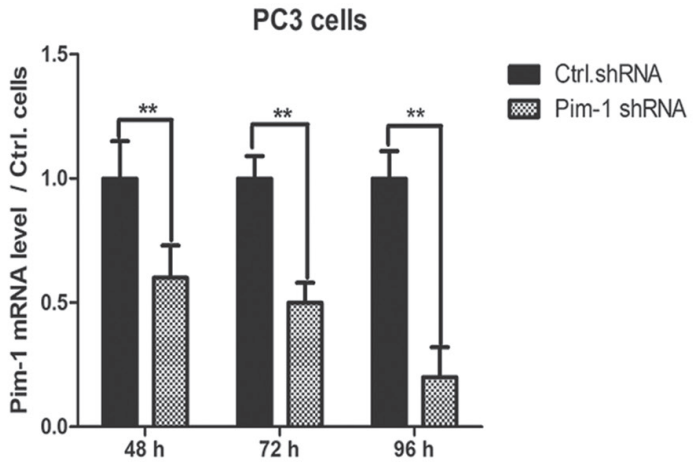

C

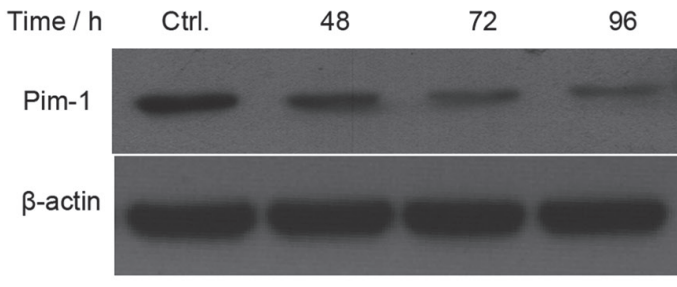

PC3 cells

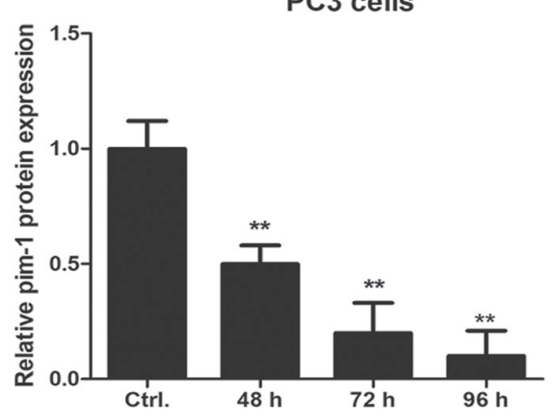

E

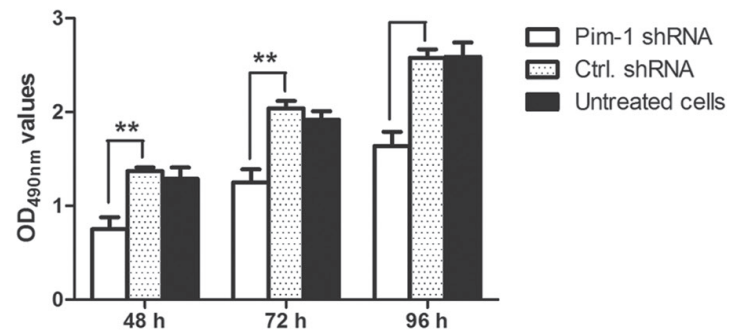

B

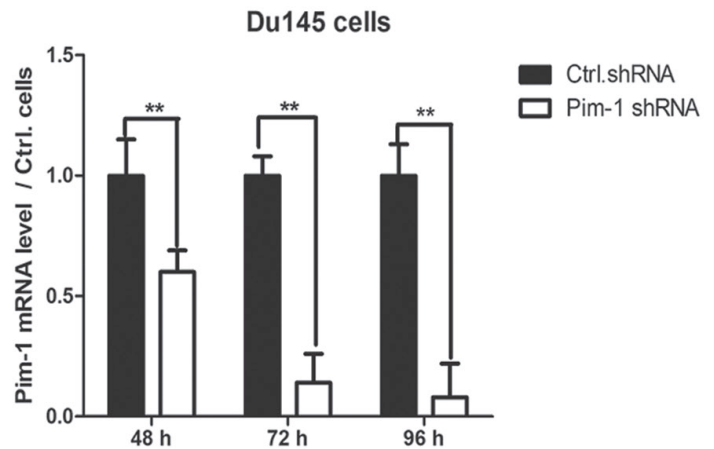

D

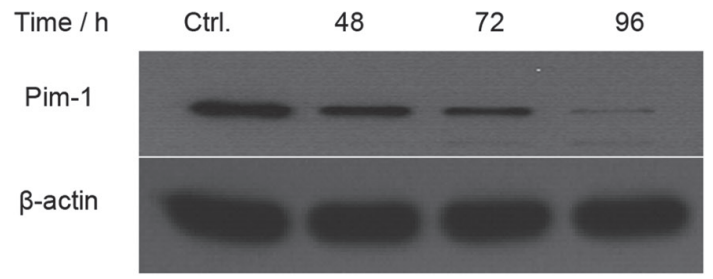

Du145 cells
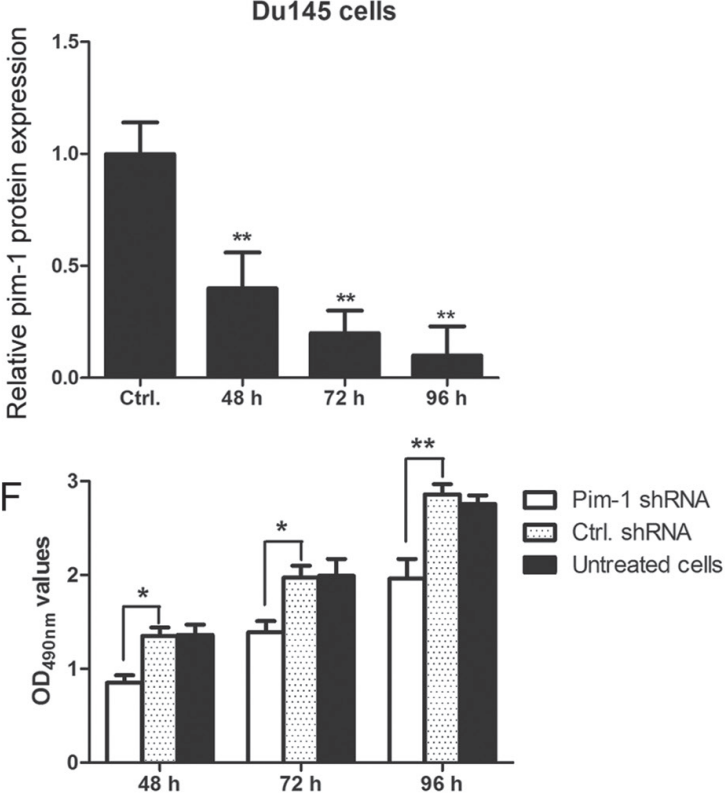

Figure 2. Pim-1 shRNA inhibits PC3 and Du145 cell viability. (A and B) Androgen independent human prostate cancer cell lines PC3 and Du145 were transfected with pim-1 or ctrl shRNA before 48, 72 and 96 h of further culture. PC-3 and Du145 cells transfected with ctrl shRNA were used as negative controls. Reverse-transcription quantitative PCR was performed to detect pim-1 mRNA levels in (A) PC3 cells and (B) DU145 cells. ${ }^{* *}$ P<0.01 vs. Ctrl. (C and D) Western blot analysis was also performed to assess pim-1 protein expression in (C) PC3 cells and (D) DU145 cells. Each experiment was repeated 3 times. Densitometry of each band in western blotting were quantified. ${ }^{* *} \mathrm{P}<0.01$ vs. Ctrl. Cell viability was determined in (E) PC-3 cells transfected with pim-1 shRNA and (F) Du145 cells transfected with pim-1 shRNA using MTT assay after 48, 72 and 96 h. ${ }^{*} \mathrm{P}<0.05$ and ${ }^{* *} \mathrm{P}<0.01$ vs. Ctrl. shRNA. ctrl, control shRNA; OD, optical density; pim-1, proto-oncogene serine/threonine-protein kinase pim-1; shRNA, short hairpin RNA.

for doxorubicin in PC3 and PC3/DDP cells were 38.91 and $258.3 \mu \mathrm{g} / \mathrm{ml}$, respectively (Fig. 3D). Thus, the IC50 values of PC3/DDP cells for the three chemotherapeutic drugs were markedly higher than that of PC3 cells. Altogether, these observations indicated that the drug-resistant PC3/DDP and its parental drug-sensitive PC3 cell lines were suitable cell models for studying chemotherapeutic drug resistance.

Pim-1 knockdown increases chemotherapeutic drug sensitivity in PC3/DDP cells. To investigate whether pim-1 serves a role in chemotherapeutic drug sensitivity in PC3/DDP cells, cells transfected with pim-1 shRNA were treated with concentrations of cisplatin or 5-fluorouracil lower than IC50. Pim-1 or control shRNA-transfected PC3/DDP cells were first treated with $0.1 \mathrm{mg} / \mathrm{ml}$ cisplatin for 24,48 and $72 \mathrm{~h}$ before cell viability was assessed using MTT assay. The viability of PC3/DDP cells transfected with pim-1 shRNA was significantly reduced compared with cells transfected with control shRNA in the presence of cisplatin at all timepoints tested (Fig. 4A). In the presence of $0.5 \mathrm{mg} / \mathrm{ml} 5$-fluorouracil, PC3/DDP cells transfected with pim-1 shRNA exhibited lower survival rates compared with cells transfected with control shRNA transfected after 24 and 48 h (Fig. 4B). The $\mathrm{IC}_{50}$ values of cisplatin in PC3 and PC3/DDP cells transfected 
A
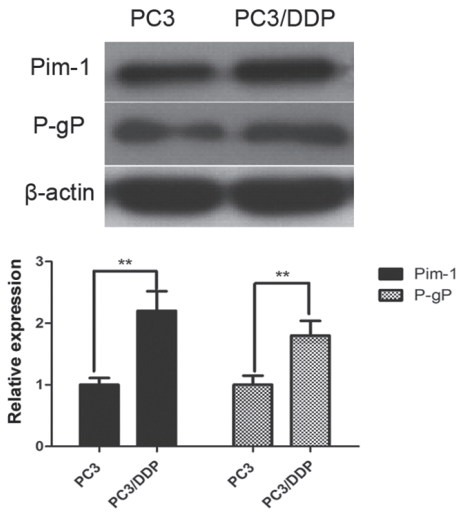

C

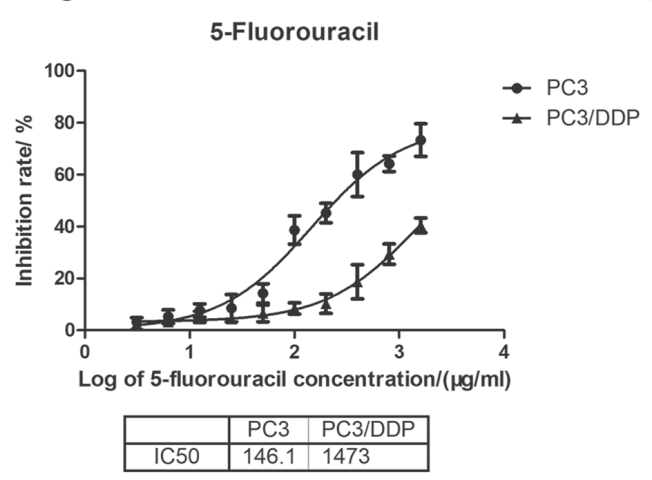

B

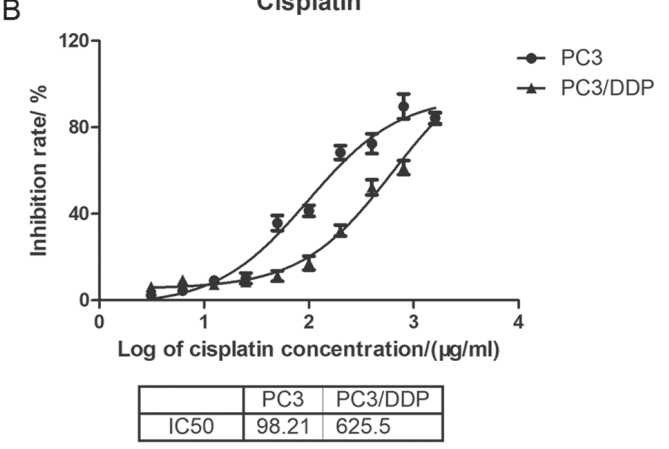

D

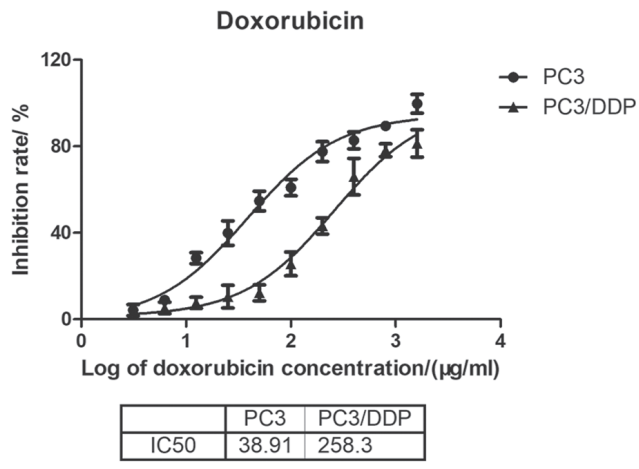

Figure 3. Expression of pim-1 and p-gp is higher in PC3/DDP cells compared with PC3 cells. (A) PC3 and PC3/DDP cells were seeded into 48-well plates for $8 \mathrm{~h}$. Pim-1 and p-gp protein expression levels were determined using western blotting analysis. $\beta$-actin was used as internal reference gene. ${ }^{* *} \mathrm{P}<0.01$ vs. PC 3 cells. PC3 cells and PC3/DDP cells were treated with three different chemotherapeutic drugs, including (B) cisplatin, (C) 5-fluorouracil and (D) doxorubicin for $48 \mathrm{~h}$. Cell viability was subsequently determined using MTT assay and their corresponding $\mathrm{IC}_{50}$ values $(\mu \mathrm{g} / \mathrm{ml})$ were calculated. Each sample was analysed in duplicate. PC3, PC3 cells; p-gp, permeability glycoprotein; pim-1, proto-oncogene serine/threonine-protein kinase pim-1.

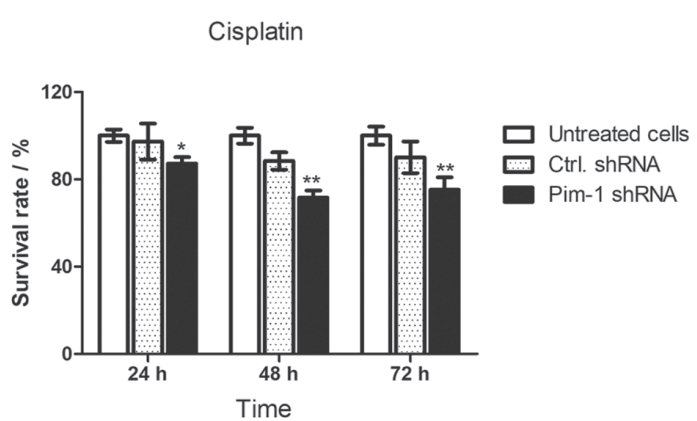

C

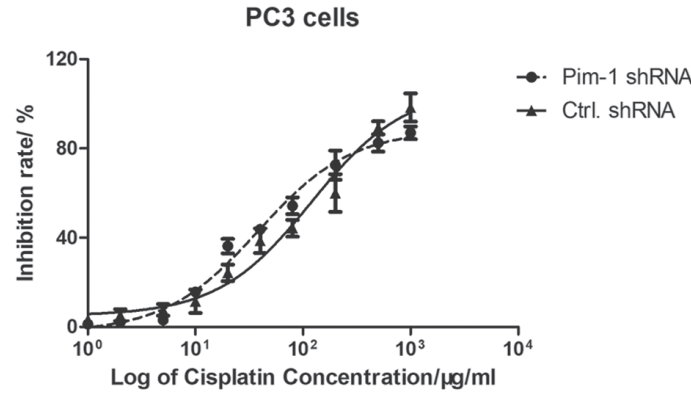

Ctrl. shRNA Pim-1 shRNA

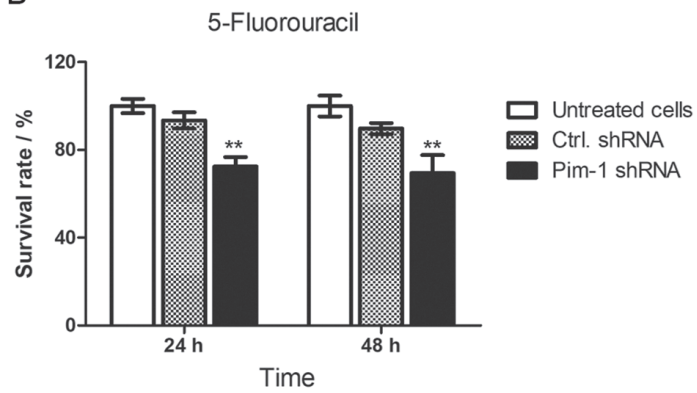

D

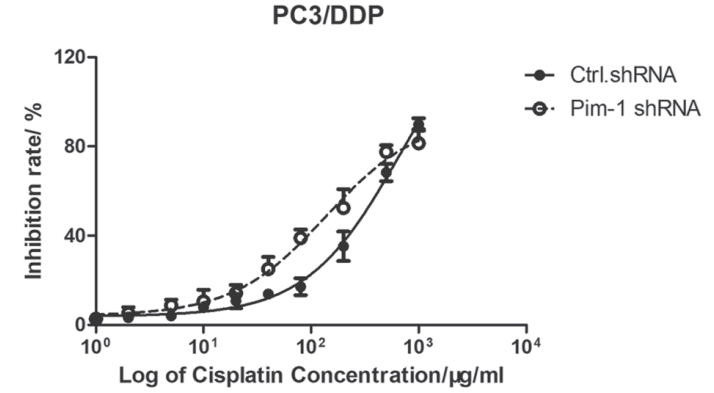

Figure 4. Pim-1 knockdown increases chemotherapeutic drug sensitivity in PC3/DDP cells. (A and B) PC3/DDP cells were transfected with pim-1 or ctrl. shRNA before (A) $0.1 \mu \mathrm{g} / \mathrm{ml}$ of cisplatin treatment for 24,48 and $72 \mathrm{~h}$ or (B) $0.5 \mu \mathrm{g} / \mathrm{ml}$ of 5-fluorouracil treatment for 24 and $48 \mathrm{~h}$. Cell viability was determined using MTT assay. Each treatment had three replicates and was repeated three times. ${ }^{*} \mathrm{P}<0.05$ and ${ }^{* *} \mathrm{P}<0.01$ vs. Ctrl. shRNA. (C and D) IC $5_{50}$ values $(\mu \mathrm{g} / \mathrm{ml})$ in (C) PC3 and (D) PC3/DDP cells transfected with pim-1 shRNA or ctrl. shRNA. Pim-1 shRNA-transfected PC3 or PC3/DDP cells exhibited lower IC s0 $_{5}$ values compared with cells transfected with control shRNA. Pim-1, proto-oncogene serine/threonine-protein kinase; $\mathrm{IC}_{50}$, half maximal inhibitory concentration; shRNA, short hairpin RNA; ctrl. shRNA, control shRNA. 
A

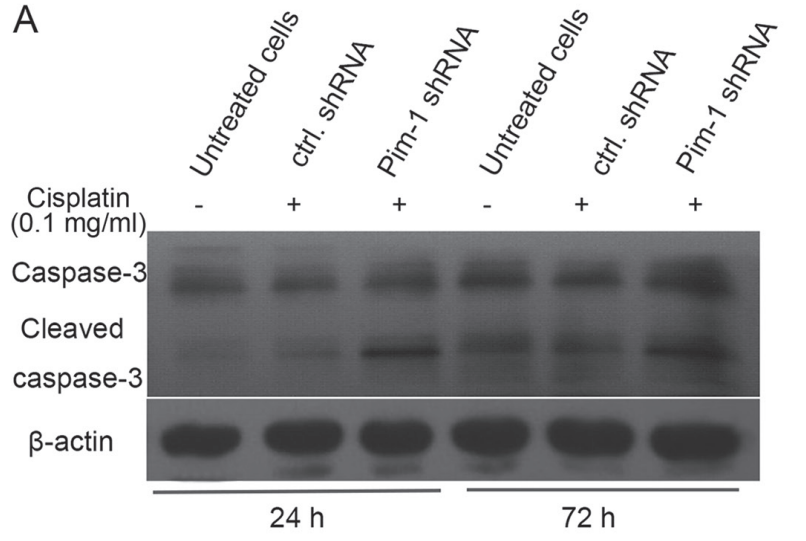

B

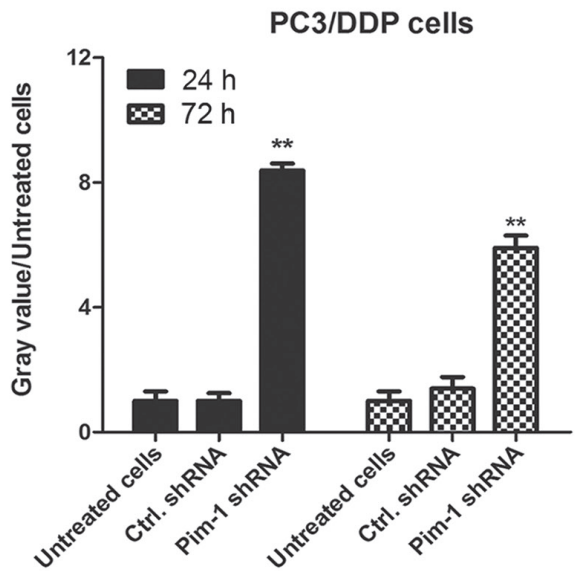

Figure 5. Pim-1 knockdown promotes caspase-3 activation in cisplatin-resistant PC3/DDP cells. (A) PC3/DDP cells were transfected with pim-1 or ctrl.shRNA for 24 and $72 \mathrm{~h}$ before the levels of caspase-3 and cleaved caspase-3 were determined using western blotting analysis. $\beta$-actin was used as internal reference. The experiment was repeated twice. (B) Densitometric analysis of caspase-3 and cleaved caspase-3 were quantified and displayed in a histogram. Untreated cells were used as negative control. ${ }^{* *} \mathrm{P}<0.01$ vs. ctrl. shRNA. Pim-1, proto-oncogene serine/threonine-protein kinase; shRNA, short hairpin RNA; ctrl. shRNA, control shRNA.

A
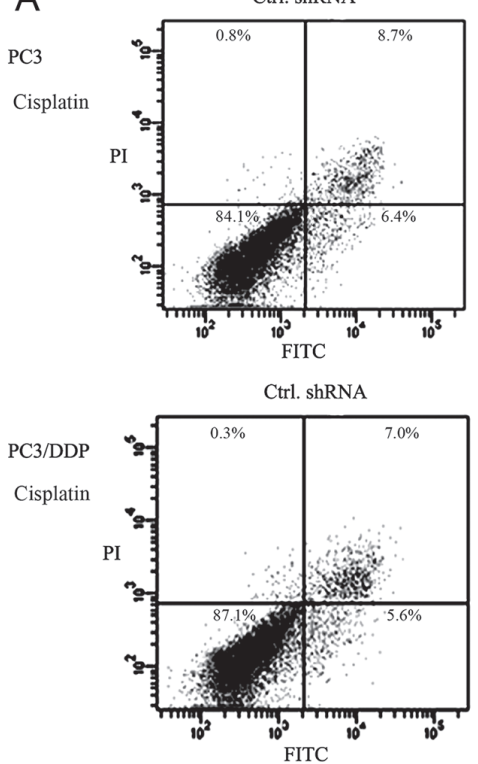
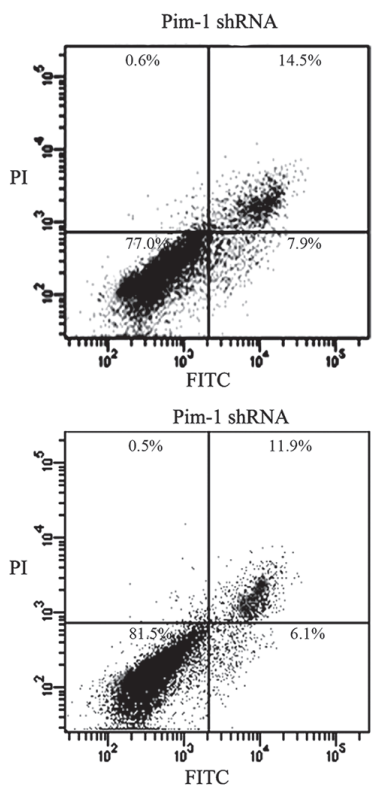

B

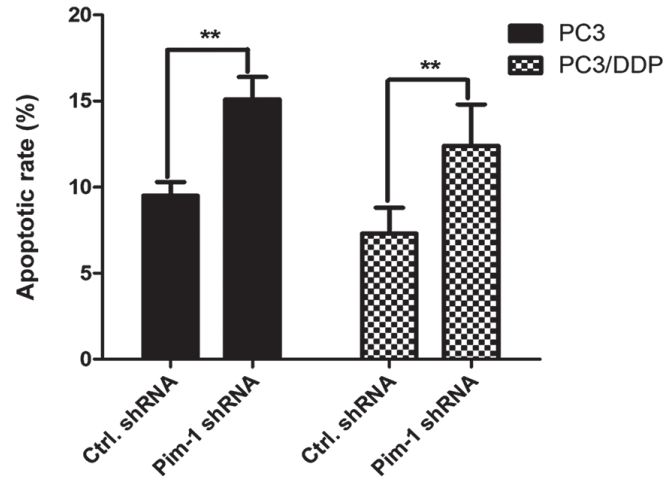

Figure 6. PC3 and PC3/DDP cells transfected with pim-1 shRNA exhibit higher apoptotic rates compared with cells transfected with ctrl.shRNA. (A) PC3 and PC3/DDP cells were transfected with pim-1 shRNA or ctrl.shRNA and treated with $0.1 \mathrm{mg} / \mathrm{ml}$ of cisplatin for $48 \mathrm{~h}$ before their respective apoptotic rates were detected using fluorescence-activated cell sorting analysis after Annexin V-FITC/PI dual staining. (B) The apoptotic rates of PC3 and PC3/DDP cells transfected with pim-1 or ctrl shRNA were calculated. ${ }^{* *} \mathrm{P}<0.01$ vs. Ctrl. shRNA transfected group. Ctrl, control; Pim-1, proto-oncogene serine/threonine-protein kinase; shRNA, short hairpin RNA.

with pim-1 shRNA and control shRNA were calculated as $38.24 \mu \mathrm{g} / \mathrm{ml}$ and $119.8 \mu \mathrm{g} / \mathrm{ml}$, respectively (3.13-fold; Fig. 4C). For PC3/DDP cells, the $\mathrm{IC}_{50}$ value for cisplatin following pim-1 shRNA transfection was calculated to be $138.3 \mu \mathrm{g} / \mathrm{ml}$, compared with $669.4 \mu \mathrm{g} / \mathrm{ml}$ in cells transfected with control shRNA (4.84-fold; Fig. 4D). In conclusion, this observation suggests that pim-1 knockdown increased the sensitivity of PC3/DDP cells to cisplatin and 5-fluorouricil.

Pim-1 knockdown promotes caspase-3 activation and induces apoptosis in PC $3 / D D P$ cells. To clarify the molecular mechanism of pim-1 in inducing chemotherapeutic drug resistance in PC3/DDP cells, the effect of pim-1 knockdown on cell apoptosis was examined. PC3/DDP cells were transfected with pim-1 or control shRNA and subsequently treated with $0.1 \mathrm{mg} / \mathrm{ml}$ cisplatin for 24 and $72 \mathrm{~h}$. The levels of caspase-3 and cleaved caspase- 3 were then determined using western blotting analysis. Following $0.1 \mathrm{mg} / \mathrm{ml}$ cisplatin treatment, the levels of cleaved caspase-3 in PC3/DDP cells transfected with pim-1 shRNA were significantly higher compared with cells transfected with control shRNA after 24 and 72 h $(\mathrm{P}<0.01$; Fig. 5). To support this finding, FACS analysis was performed to measure the apoptotic rate of PC3 and PC3/DDP cells transfected with pim-1 or control shRNA, following $48 \mathrm{~h}$ of $0.1 \mathrm{mg} / \mathrm{ml}$ cisplatin treatment. In the presence of cisplatin, the apoptotic rates of $\mathrm{PC} 3$ and $\mathrm{PC} 3 / \mathrm{DDP}$ cells transfected with pim-1 shRNA were significantly higher compared with those transfected with control shRNA (Fig. 6). This observation 
indicates further that pim-1 knockdown increased apoptotic rates in cisplatin-resistant PC3/DDP cells.

\section{Discussion}

Prostate cancer is a heterogeneous disease in male reproductive system, which consists of androgen-dependent and androgen-independent varieties (22). Androgen deprivation therapy has achieved remarkable results in the treatment of advanced prostate cancer, and hormone therapy has gradually become an important method for the treatment of prostate cancer (23). For androgen-dependent prostate cancer, surgical castration therapy has a certain therapeutic effect (24). However, in patients with advanced prostate cancer, the disease usually turns into non-androgen-dependent prostate cancer after a period of time, which makes castration treatment less effective. There is currently no effective treatment for androgen-independent prostate cancer (24). The purpose of the present study was to find a new and effective method for the prevention and treatment of advanced prostate cancer and AIPC. In particular, the effects of pim-1 on resistance to chemotherapy were explored in PC3/DDP cells and its parental cell line PC3. However, the current study had certain limitations. Comparisons between androgen dependent and androgen-independent prostate cancer cells, primary cell lines and animal models were not included in this study. In future research, clinical specimens should be collected and used to test and compare the levels of pim-1 in androgen dependent and androgen-independent prostate cancer. Furthermore, an animal model should be used to test the tumorigenesis of pim-1 shRNA- and control shRNA-transfected cells.

Three members of proto-oncogene serine/threonine kinase family have been identified, including pim-1, pim-2 and pim-3 $(25,26)$. It has been reported that pim-1 is involved in regulating cell cycle progression and apoptosis (26); and has been detected to be heavily expressed in numerous cancers including prostate cancer, Burkitt's lymphoma, oral cancer and a variety of hematopoietic lymphomas $(27,28)$. Therefore, to study the role of pim-1 in the prostate cancer physiology, endogenous pim-1 expression was knocked down in androgen-independent prostate cancer cells, including PC3, DU145 and PC3/DDP, using the shRNA approach. The present study revealed that pim-1 knockdown resulted in reduced viability in AIPC cell lines. Pim-1 knockdown markedly increased the activation of caspase-3 and promoted cell apoptosis of chemotherapeutic drug-resistant PC3/DDP cells, which was also confirmed by FACS assay. It has been reported that pim-1 is the target gene of the Janus kinase and STAT signaling pathway. Additionally, pim-1 is involved in the regulation of cell apoptosis and cell cycle progression by interacting with the PI3K/Akt signaling pathway (29).

The role of pim-1 in chemotherapeutic drug sensitivity of prostate cancer cells was also tested. P-gp, encoded by the multi-drug resistance protein 1 gene, has been reported to contribute to drug resistance in cancer cells, which serves an important role in drug disposition and distribution (30). It was found that pim-1 knockdown significantly increased PC3/DDP cell sensitivity to cisplatin, 5-fluorouracil and doxorubicin, which could potentially reduce the drug dose required for chemotherapy and increase its antitumor potency, whilst reducing the risk of drug toxicity.

In conclusion, results from the present study suggested that pim-1 knockdown suppressed AIPC cell viability and increased chemotherapeutic drug sensitivity in cisplatin-resistant PC3/DDP cells. These results may be helpful for the clinical therapy of AIPC and addressing resistance to chemotherapy drugs in prostate cancers.

\section{Acknowledgements}

Not applicable.

\section{Funding}

The present study was supported by grants from The Natural Science Foundation of Jiangsu Province (grant no. BK20160481), The Natural Science Foundation of Yangzhou (grant no. YZ2015111), Project for Jiangsu Commission of Health (grant nos. QNRC2016360 and H2018108) and Six Talent Peaks Project in Jiangsu Province (grant no. WSW-258).

\section{Availability of data and materials}

The datasets used and/or analyzed during the current study are available from the corresponding author on reasonable request.

\section{Authors' contributions}

SWL designed the studies and carried out literature research; $\mathrm{XZ}$ performed the experimental studies; YYS and PW analyzed the data and performed the statistical analysis; CFY assisted in performing the experiments and prepared the manuscript.

\section{Ethics approval and consent to participate}

Not applicable.

\section{Patient consent for publication}

Not applicable.

\section{Competing interests}

The authors declare that they have no competing interests.

\section{References}

1. Mahmoud AM, Yang W and Bosland MC: Soy isoflavones and prostate cancer: A review of molecular mechanisms. J Steroid Biochem Mol Biol 140: 116-132, 2014

2. Ma X, Xiao Z, Li X, Wang F, Zhang J, Zhou R, Wang J and Liu L: Prognostic role of circulating tumor cells and disseminated tumor cells in patients with prostate cancer: A systematic review and meta-analysis. Tumour Biol 35: 5551-5560, 2014.

3. Nevedomskaya E, Baumgart SJ and Haendler B: Recent advances in prostate cancer treatment and drug discovery. Int J Mol Sci 19: E1359, 2018.

4. Eisenberger M: Research in drug development for advanced prostate cancer. Clin Adv Hematol Oncol 16: 42-44, 2018. 
5. González Á, García de Durango C, Alonso V, Bravo B, Rodríguez de Gortázar A, Wells A, Forteza J and Vidal-Vanaclocha F: Distinct osteomimetic response of androgen-dependent and independent human prostate cancer cells to mechanical action of fluid flow: Prometastatic implications. Prostate 77: 321-333, 2017.

6. Williams RM, Hajiran CJ, Nayeem S and Sooter LJ: Identification of an antibody fragment specific for androgen-dependent prostate cancer cells. BMC Biotechnol 14: 81, 2014.

7. Zhang C, Li P, Wen Y, Feng G, Liu Y, Zhang Y, Xu Y and Zhang Z: The promotion on cell growth of androgen-dependent prostate cancer by antimony via mimicking androgen activity. Toxicol Lett 288: 136-142, 2018.

8. Li K, Li Y, Zhou D, Fan Y, Guo H, Ma T, Wen J, Liu D and Zhao L: Synthesis and biological evaluation of quinoline derivatives as potential anti-prostate cancer agents and Pim-1 kinase inhibitors. Bioorg Med Chem 24: 1889-1897, 2016.

9. Kim JE, Son JE, Jeong H, Joon Kim D, Seo SK, Lee E, Lim TG Kim JR, Chen H, Bode AM, et al: A novel cinnamon-related natural product with Pim-1 inhibitory activity inhibits leukemia and skin cancer. Cancer Res 75: 2716-2728, 2015.

10. Wang J, Li G, Li B, Song H, Shang Z, Jiang N and Niu Y: Androgen deprivation therapy has no effect on Pim-1 expression in a mouse model of prostate cancer. Oncol Lett 13: 4364-4370, 2017.

11. Tamura RE, de Luna IV, Lana MG and Strauss BE: Improving adenoviral vectors and strategies for prostate cancer gene therapy. Clinics (Sao Paulo) 73 (Suppl 1): e476s, 2018.

12. Grozescu $T$ and Popa F: Immunotherapy and gene therapy in prostate cancer treatment. J Med Life 10: 54-55, 2017.

13. Souza AG, Bastos VAF, Silva IBB, Marangoni K and Goulart VA: Different gene therapy strategies: A overview for prostate cancer. Curr Gene Ther 16: 287-291, 2016.

14. Cai Z, Lv H, Cao W, Zhou C, Liu Q, Li H and Zhou F: Targeting strategies of adenovirusmediated gene therapy and virotherapy for prostate cancer (Review). Mol Med Rep 16: 6443-6458, 2017

15. Livak KJ and Schmittgen TD: Analysis of relative gene expression data using real-time quantitative PCR and the 2(-Delta Delta C(T)) method. Methods 25: 402-408, 2001.

16. Abel SDA and Baird SK: Honey is cytotoxic towards prostate cancer cells but interacts with the MTT reagent: Considerations for the choice of cell viability assay. Food Chem 241: 70-78, 2018.

17. Kumar P, Nagarajan A and Uchil PD: Analysis of cell viability by the MTT Assay. Cold Spring Harb Protoc 2018: 2018.

18. Ma S, Tan W, Du B, Liu W, Li W, Che D and Zhang G: Oridonin effectively reverses cisplatin drug resistance in human ovarian cancer cells via induction of cell apoptosis and inhibition of matrix metalloproteinase expression. Mol Med Rep 13: 3342-3348, 2016.
19. Tian J, Liu R and Qu Q: Role of endoplasmic reticulum stress on cisplatin resistance in ovarian carcinoma. Oncol Lett 13: 1437-1443, 2017

20. Swellmeen L, Shahin R, Al-Hiari Y, Alamiri A, Hasan A and Shaheen O: Structure based drug design of Pim-1 kinase followed by pharmacophore guided synthesis of quinolone-based inhibitors. Bioorg Med Chem 25: 4855-4875, 2017.

21. Wu J, Zhang Q, Wuu YR, Zou S and Hei TK: Cytoplasmic irradiation induces metabolic shift in human small airway epithelial cells via activation of Pim-1 kinase. Radiat Res 187: 441-453, 2017.

22. Etheridge T, Liou J, Downs TM, Abel EJ, Richards KA and Jarrard DF: The impact of celecoxib on outcomes in advanced prostate cancer patients undergoing androgen deprivation therapy. Am J Clin Exp Urol 6: 123-132, 2018.

23. Thamilselvan V, Menon M, Stein GS, Valeriote $F$ and Thamilselvan S: Combination of carmustine and selenite inhibits EGFR mediated growth signaling in androgen-independent prostate cancer cells. J Cell Biochem 118: 4331-4340, 2017.

24. Cha S, Shin DH, Seok JR and Myung JK: Differential proteome expression analysis of androgen-dependent and -independent pathways in LNCaP prostate cancer cells. Exp Cell Res 359: 215-225, 2017.

25. Xu J, Xiong G, Cao Z, Huang H, Wang T, You L, Zhou L, Zheng L, Hu Y, Zhang T and Zhao Y: PIM-1 contributes to the malignancy of pancreatic cancer and displays diagnostic and prognostic value. J Exp Clin Cancer Res 35: 133, 2016.

26. Liu Z, Liu H, Yuan X, Wang Y, Li L, Wang G, Song J, Shao Z and Fu R: Downregulation of Pim-2 induces cell cycle arrest in the G0/G1 phase via the p53-non-dependent p21 signaling pathway. Oncol Lett 15: 4079-4086, 2018.

27. Tursynbay Y, Zhang J, Li Z, Tokay T, Zhumadilov Z, Wu D and Xie Y: Pim-1 kinase as cancer drug target: An update. Biomed Rep 4: 140-146, 2016

28. Ouhtit A, Muzumdar S, Gupta I, Shanmuganathan S and Tamimi Y: Understanding the functional discrepancy of Pim-1 in cancer. Front Biosci (Elite Ed) 7: 208-214, 2015.

29. Jiang W, Chen Y, Song X, Shao Y, Ning Z and Gu W: Pim-1 inhibitor SMI-4a suppresses tumor growth in non-small cell lung cancer via PI3K/AKT/mTOR pathway. OncoTargets Ther 12: 3043-3050, 2019

30. Ma X, Hu M, Wang H and Li J: Discovery of traditional Chinese medicine monomers and their synthetic intermediates, analogs or derivatives for battling P-gp-mediated multi-drug resistance. Eur J Med Chem 159: 381-392, 2018. 